\title{
Transcriptome Analysis of a Wheat Near-Isogenic Line Pair Carrying Fusarium Head Blight-Resistant and -Susceptible Alleles
}

\author{
Haiyan Jia, Seungho Cho, and Gary J. Muehlbauer \\ Department of Agronomy and Plant Genetics, 411 Borlaug Hall, 1991 Upper Buford Circle University of Minnesota, \\ St. Paul, MN 55108, U.S.A.
}

Submitted 4 November 2008. Accepted 29 May 2009.

Fusarium head blight (FHB), caused primarily by Fusarium graminearum, decreases grain yield and quality in wheat and barley. Disease severity, deoxynivalenol (DON), fungal biomass, and transcript accumulation were examined in a wheat near-isogenic line pair carrying either the resistant or susceptible allele for the chromosome 3BS FHB-resistance quantitative trait locus (Fhb1). Fhb1 restricts spread of disease symptoms but does not provide resistance to initial infection or initial DON accumulation. Wheat exhibits both induction and repression of large sets of gene transcripts during $F$. graminearum infection. In addition, a difference in the general timing of transcript accumulation in plants carrying either the resistant or susceptible allele at the Fhb1 locus was detected, and 14 wheat gene transcripts were detected that exhibited accumulation differences between the resistant and susceptible alleles. These results indicate that these may be host responses that differentiate the resistant from the susceptible interaction. Comparative analysis of the wheat-F. graminearum and the barley- $F$. graminearum interactions revealed a large set of conserved transcript accumulation patterns. However, we also detected gene transcripts that were repressed in wheat but not in barley. Based on the disease symptoms, transcript accumulation data, and comparative analysis of the barley and wheat host response to $F$. graminearum infection, we developed an integrated model for the interactions of wheat and barley with $F$. graminearum.

Fusarium head blight (FHB) or scab, caused primarily by Fusarium graminearum Schwabe (teleomorph Gibberella zeae [Schweinitz] Petch), is an economically damaging disease on wheat (Triticum aestivum L.) and barley (Hordeum vulgare L.) in North America and worldwide (McMullen et al. 1997; Parry 1995). From 1991 to 1997 , the estimated loss due to FHB was about $\$ 1.3$ billion in the United States (Johnson et al. 2003). Disease develops in the spike, resulting in low-weight kernels and reduced yield. FHB not only decreases grain yield but also lowers grain quality by accumulating trichothecene mycotoxins such as deoxynivalenol (DON), 15-acetyldeoxynivalenol (15ADON), and 3-acetyldeoxynivalenol (3-ADON), which are

Corresponding author: Gary J. Muehlbauer; E-mail: muehl003@umn.edu; Telephone: +1.612.625.6228; Fax: +1.612.625.1268.

* The $\boldsymbol{e}$-Xtra logo stands for "electronic extra" and indicates that eight tables are published online. harmful to humans and animals (Desjardins 2006; Desjardins and Hohn 1997).

F. graminearum invades wheat spikes and causes FHB through a series of complex pathways and mechanisms (Bushnell et al. 2003). The fungus can enter through the stomatal pores or grow between or directly through the floral bracts. F. culmorum (a Fusarium species that can also cause FHB) infection of wheat results in cell-wall degradation, and barley infected by $F$. graminearum exhibits the accumulation of fungal gene transcripts that encode cell wall-degrading enzymes (Güldener et al. 2006; Kang and Buchenauer 2000). These results indicate that cell wall-degrading enzymes are an important component of infection. Also during infection, fungal gene transcripts encoding trichothecene biosynthetic enzymes are detected (Güldener et al. 2006) and trichothecene mycotoxins are produced that inhibit protein synthesis and increase virulence (Desjardins and Hohn 1997; Proctor et al. 1995). Finally, the fungus colonizes the ovary and floral bracts and the infected tissue becomes necrotic and bleached (Bushnell et al. 2003; Pritsch et al. 2000).

Resistance to FHB in wheat is primarily defined by type I (resistance to initial infection) and type II (resistance to spread of the disease within a spike) resistance (Mesterhazy 1995). Type I and II resistances have been identified in several wheat genotypes and have been used in breeding programs to increase resistance (Bai and Shaner 2004). Interestingly, barley, including susceptible genotypes, exhibits natural type II resistance. Thus, comparing the responses in wheat and barley to $F$. graminearum infection may reveal the mechanisms of type II resistance and a greater understanding of the wheat $-F$. graminearum interaction.

To identify regions of the wheat genome that control FHB resistance, multiple quantitative trait loci (QTL) mapping studies have been conducted. Mapping studies with the type II resistant cultivar Sumai 3 and its derivatives have identified a major QTL on chromosome 3BS referred to as Fhbl (Anderson et al. 2001; Bai et al. 1999; Buerstmayr et al. 2002; Liu et al. 2006; Waldron et al. 1999; Zhou et al. 2002). The Sumai 3-derived Fhbl allele explains 20 to $60 \%$ of the variation for FHB resistance (Pumphrey et al. 2007). Lemmens and associates (2005) showed that plants carrying the Fhbl resistant allele convert DON to DON-3-glucoside, a derivative that exhibits reduced toxicity. Poppenberger and associates (2003) showed that an Arabidopsis uridine 5' diphosphate (UDP)-glucosyltransferase converts DON to DON-3-glucoside. Thus, Lemmens and associates (2005) proposed that the wheat Fhbl locus encodes a DON-glucosyltransferase or, alternatively, a gene that regulates a DON-glucosyltransferase. 
Wheat responds to $F$. graminearum infection by inducing several classes of biotic and abiotic stress response genes (Ansari et al. 2007; Bernardo et al. 2007; Golkari et al. 2007; Hill-Ambroz et al. 2006; Jansen et al. 2005; Kong et al. 2005; Pritsch et al. 2000; 2001; Steiner et al. 2009; Walter et al. 2008; Zhou et al. 2005). Ansari and associates (2007) showed that transcripts encoding a bZIP transcription factor were upregulated in DON-treated plants segregating for the Fhbl resistant allele. Steiner and associates (2009) used genetic stocks carrying resistant or susceptible alleles at the Fhbl locus and another QTL for FHB resistance on chromosome 5A and found 14 genes differentially expressed between the resistant and susceptible genotypes. In addition, DON inoculation of wheat stems revealed the production of reactive oxygen species and DNA laddering, both characteristic of programmed cell death (PCD) responses (Desmond et al. 2008). Although multiple studies investigating the wheat response to $F$. graminearum infection and DON inoculation have been conducted, a genome-wide assessment of the wheat response to $F$. graminearum infection and comparisons between nearisogenic lines (NIL) carrying the resistant and susceptible $F h b 1$ alleles have not been conducted.

More is known about the overall barley response to $F$. graminearum infection. Using the Barley1 Affymetrix GeneChip probe array, which represents 22,349 barley genes (Close et al. 2004), the host response in barley to $F$. graminearum infection was examined (Boddu et al. 2006). A total of 467 gene transcripts responded to $F$. graminearum infection, and the gene expression patterns defined early, intermediate, and late stages of infection in barley. The greatest number of host transcripts and initial DON accumulation were observed at the intermediate stage, indicating that trichothecene accumulation plays an important role in inducing the host response. The Barley1 GeneChip was also used to examine transcript accumulation in barley after infection with trichothecene-producing and -nonproducing strains of $F$. graminearum (Boddu et al. 2007). Genes specifically responding to trichothecene accumulation were detected, and two opposing host responses were proposed. One class of induced genes encoded trichothecene-detoxifying enzymes and transporters that may reduce the impact of trichothecenes, and the other class encoded proteins related to cell death and ubiquitination that may promote establishment of the disease.

In this study, we used the Affymetrix wheat GeneChip probe array to examine the transcript accumulation in a NIL pair carrying either the resistant or susceptible allele at the wheat Fhbl locus during F. graminearum infection. We also studied the disease phenotypes in this NIL pair. The objectives of this study were i) to examine the relationship between DON accumulation, fungal biomass, and disease severity in a wheat NIL pair carrying either the $F h b 1$ resistant or susceptible allele, ii) to describe transcriptome changes during the wheat- $F$. graminearum interaction, iii) to identify genes that define the Fhbl resistant and susceptible phenotypes, and iv) to develop an integrated model of the wheat and barley host response to $F$. graminearum infection.

\section{RESULTS}

Disease severity, DON accumulation, and fungal biomass in a wheat NIL pair carrying either the $F$ hb1 resistant or susceptible allele.

Disease severity on a wheat NIL pair carrying either the Fhbl resistant or susceptible allele was assessed at 21 days after point-inoculation with $F$. graminearum. The difference in percent disease severity was statistically significant $(P \leq 0.0001)$ between the two NIL carrying the resistant $(21 \pm 4.0)$ and susceptible $(52 \pm 13)$ alleles (Fig. 1A). On the resistant NIL, disease symptoms were restricted to the initially inoculated spikelets and did not spread to the adjacent spikelets. In contrast, on the susceptible NIL, the disease symptoms spread to the adjacent spikelets. At $48 \mathrm{~h}$ after inoculation (hai), the inoculated spikelets on both the resistant and susceptible NIL showed necrotic tissue (Fig. 1B) and, by 96 hai, showed bleaching (Fig. 1C). For both timepoints, the susceptible NIL exhibited more severe disease phenotypes.
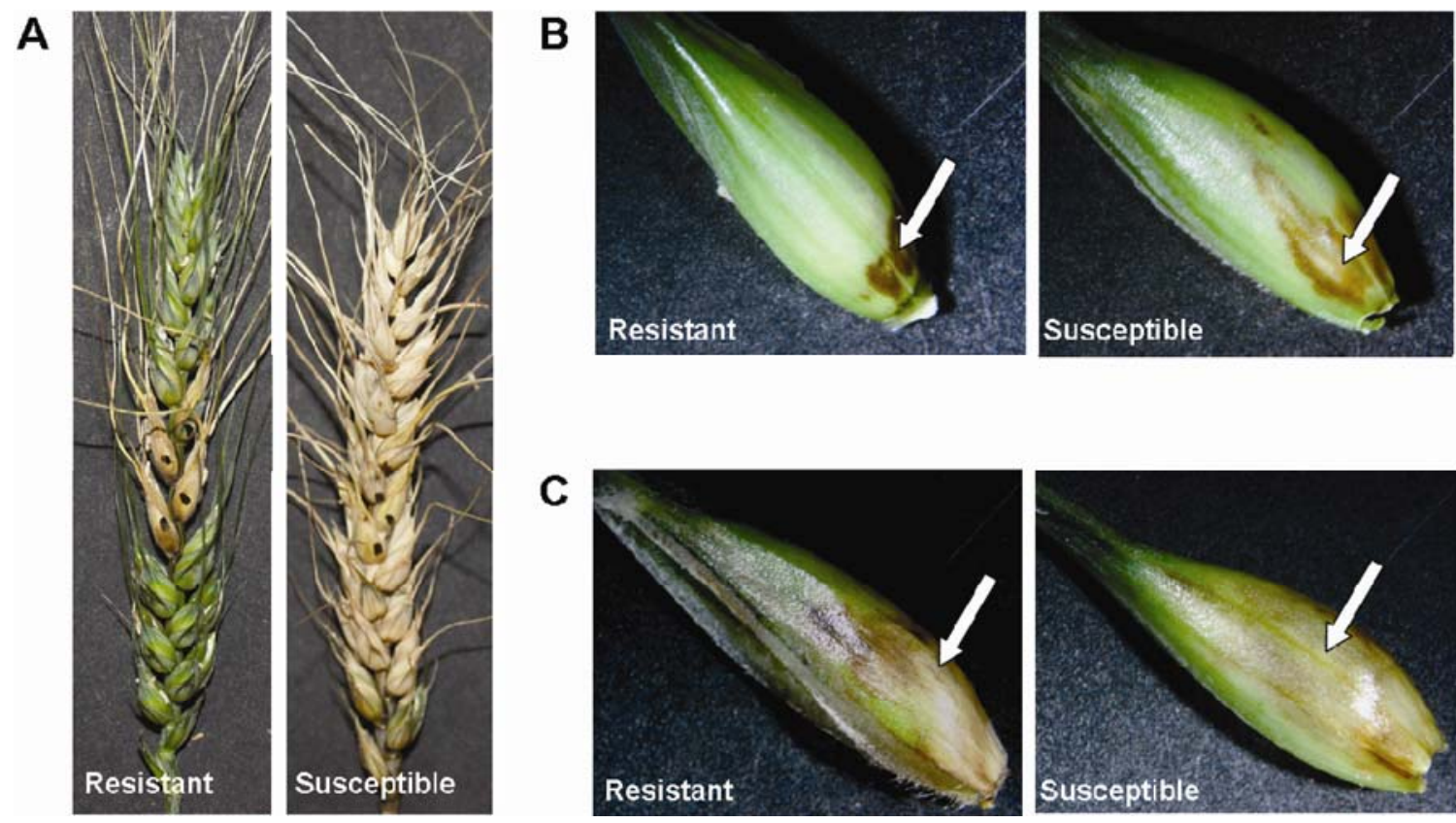

Fig. 1. Disease phenotypes on wheat plants carrying the resistant or susceptible Fhb1 allele after point-inoculation with Fusarium graminearum. A, At 21 days after inoculation (dai), B, $48 \mathrm{~h}$ after inoculation (hai), and C, 96 hai. Arrows point to necrotic (A) and bleached (B) regions. The light green areas in A were not pathogen-induced bleaching. Resistant indicates plants carrying the Fhb1 resistant allele. Susceptible indicates plants carrying the Fhb1 susceptible allele. 
The accumulation of DON (Table 1) and ergosterol (an indicator of fungal biomass) (Table 1) in the point-inoculated and noninoculated wheat spikelets of the NIL pair was quantified at 48 and $96 \mathrm{~h}$ after $F$. graminearum and water inoculation. DON concentration increased in $F$. graminearum-inoculated wheat spikelets at 96 hai compared with 48 hai in both the resistant and susceptible NIL. However, the difference between the resistant and susceptible NIL was not significant at either timepoint $(P<0.01)$. Ergosterol concentration also increased in $F$. graminearum-inoculated wheat spikelets at 96 hai compared with 48 hai. The difference between the resistant and susceptible NIL was not significant $(P<0.01)$. We did not detect DON or ergosterol in the water-inoculated spikelets. Noninoculated wheat spikelets adjacent to the point-inoculation sites were also sampled at 48 and 96 hai and assayed for DON and ergosterol concentration (Table 1). We did not detect DON or ergosterol in the noninoculated spikelets adjacent to the $F$. graminearum - or water-inoculated spikelets in the resistant NIL at either timepoint. However, in the susceptible NIL, we detected low amounts of DON and ergosterol at both timepoints in the noninoculated spikelets adjacent to the $F$. graminearum-inoculated spikelets.

\section{Wheat host response to $F$. graminearum infection.}

Affymetrix Wheat GeneChip was used to examine transcript accumulation in a NIL pair carrying either the Fhbl resistant or susceptible allele at 48 and $96 \mathrm{~h}$ after point-inoculation with $F$. graminearum or a mock water control. We first examined the number of transcripts exhibiting differential accumulation between $F$. graminearum - and mock water-inoculated plants $(P \leq$ $0.0001, \geq 2.0$ fold). By summing the unique transcripts, we detected 2,141 transcripts exhibiting increased accumulation after F. graminearum infection at one or both 48 and 96 hai (Fig. 2A). Of these 2,141 transcripts, 1,904 and 2,065 were detected in the resistant and susceptible genotypes, respectively (Fig. 2A). Three groups were detected: i) 1,828 transcripts in both the resistant and susceptible genotypes (Supplementary Table 1); ii) 76 transcripts only in the resistant genotype (Supplementary Table 2); and iii) 237 transcripts only in the susceptible genotype (Supplementary Table 3). More transcripts were detected in the resistant genotype $(1,618)$ than the susceptible genotype $(1,370)$ at 48 hai. However, at 96 hai more transcripts were detected in the susceptible genotype $(2,018)$ than the resistant genotype $(1,638)$.

We also detected 2,847 unique transcripts exhibiting decreased accumulation after $F$. graminearum inoculation at either one or both 48 and 96 hai. Of these 2,847 transcripts, 1,990 and 2,637 were detected in the resistant and susceptible genotypes, respectively (Fig. 2B). Three groups were identified, including i) 1,780 transcripts in both the resistant and susceptible genotypes (Supplementary Table 4); ii) 210 transcripts only in the resistant genotype (Supplementary Table 5); and iii) 857 transcripts only in the susceptible genotype (Supplementary Table 6). More gene transcripts exhibited decreased accumulation in the resistant genotype (774) than the susceptible genotype (171) at 48 hai. However, at 96 hai, more genes exhibited decreased accumulation in the susceptible genotype $(2,630)$ than the resistant genotype $(1,684)$.

\section{Wheat gene annotations.}

Annotations were assigned to all of the genes that exhibited differential transcript accumulation between $F$. graminearum and mock water inoculation and were placed into broad classes including cell death-related, cell wall-related, chromatin related, defense response, hormone-related, membrane-related, metabolism, miscellaneous, photosystem-related, regulatory, ribosomal protein, stress response, transporter, putative trichothecene detoxification and transport, ubiquitination, and unknown (Table 2). There were a variety of genes within the general broad classes that exhibited either increased or decreased transcript accumulation in $F$. graminearum-infected plants in both genotypes at either one or both 48 and 96 hai (Table 2). These genes were not identified by the same probeset but were given a similar annotation. These genes encode proteins with general functions including defense response (e.g., pathogenesis-related, phenylpropanoid pathway enzymes, oxidative burst-related, cytochrome P450) and metabolism (e.g., tryptophan biosynthesis). We examined the gene transcripts that exhibited increased or decreased transcript accumulation with regard to what is known about host responses in the wheatand barley $-F$. graminearum interaction, other plant-pathogen interactions, and the disease symptoms we observed during $F$. graminearum infection of wheat (Fig. 3; Supplemental Tables 7 and 8).

Several plant hormones, including jasmonic acid (JA) and ethylene (ET), are involved in plant-pathogen interactions (Glazebrook 2005; Spoel et al. 2007). Thus, we examined our data for gene transcripts encoding JA- and ET-related proteins that exhibited differential accumulation in F. graminearuminoculated compared with control mock water-inoculated plants in both genotypes. We identified 14 transcripts exhibiting increased accumulation that either encode JA biosynthetic enzymes (e.g., 12-oxo-phytodienoic acid reductase) or respond to JA (e.g., jasmonate-induced protein) (Fig. 3A). Eight transcripts encoding ET-induced esterase exhibited increased accumulation after $F$. graminearum infection (Fig. 3A). These results indicate that the JA and ET signaling pathways are functioning during the wheat $-F$. graminearum interaction.

Trichothecenes have been shown to be virulence factors in wheat and barley (Proctor et al. 1995). Two classes of genes have been shown to reduce the impact of trichothecenes, namely, UDP-glucosyltransferases (Poppenberger et al. 2003) that detoxify trichothecenes and $\mathrm{ABC}$ transporters (Muhitch et al. 2000) that transport trichothecenes out of the cytoplasm.

Table 1. Deoxynivalenol and ergosterol concentration in a wheat near-isogenic line pair carrying either the Fhb1-resistant or -susceptible allele pointinoculated with Fusarium graminearum

\begin{tabular}{|c|c|c|c|c|c|c|c|c|}
\hline \multirow[b]{2}{*}{ Sample ${ }^{\text {b }}$} & \multicolumn{4}{|c|}{ Deoxynivalenol concentration $^{\text {a }}$ (ppm) } & \multicolumn{4}{|c|}{ Ergosterol concentration $^{\text {a }}$ (ppm) } \\
\hline & F48 & F96 & W48 & W96 & F48 & F96 & W48 & W96 \\
\hline Resistant, inoculated & $2.83 \pm 1.36$ & $69.37 \pm 4.25$ & 0 & 0 & $4.07 \pm 0.75$ & $35.7 \pm 9.73$ & 0 & 0 \\
\hline Resistant, noninoculated & 0 & 0 & 0 & 0 & 0 & 0 & 0 & 0 \\
\hline Susceptible, inoculated & $3.04 \pm 2.89$ & $71.97 \pm 18.52$ & 0 & 0 & $4.97 \pm 4.84$ & $53.23 \pm 18.55$ & 0 & 0 \\
\hline Susceptible, noninoculated & $0.92 \pm 1.54$ & $0.69 \pm 0.89$ & 0 & 0 & $1.17 \pm 2.02$ & $0.5 \pm 0.7$ & 0 & 0 \\
\hline
\end{tabular}

${ }^{a}$ Deoxynivalenol and ergosterol concentrations \pm standard deviation were derived from three replications. $\mathrm{F}$ and $\mathrm{W}=F$. graminearum and water inoculation, respectively; 48 and $96=\mathrm{h}$ after inoculation. Deoxynivalenol and ergosterol concentration between the resistant and susceptible genotypes was not significantly different $(P<0.01)$.

${ }^{\mathrm{b}}$ Resistant and Susceptible indicates plants carrying the Fhbl resistant or susceptible alleles, respectively. Inoculated indicates spikelets that were inoculated and sampled. Noninoculated indicates spikelets adjacent to the inoculated spikelets that were sampled. 
We detected 12 gene transcripts encoding $\mathrm{ABC}$ transporters and 16 gene transcripts encoding UDP-glucosyltransferases that were induced in both genotypes during infection (Fig. $3 \mathrm{~A})$. We only detected one ABC transporter and four UDPglucosyltransferases that were repressed in both genotypes. These data indicate that wheat is responding to trichothecene accumulation by expressing transcripts encoding putative trichothecene-detoxifying and transport functions.

We also examined our data for gene transcripts encoding transcription factors. The Arabidopsis NF-X1 transcription factor has been shown to be induced upon treatment of T-2 toxin, a trichothecene mycotoxin, and that it functions as a negative regulator of trichothecene-induced defense responses (Asano et al. 2007; Masuda et al. 2007). We identified two gene transcripts that encode NF-X1-like transcription factors that exhibited increased accumulation (Fig. 3A). We also identified thirteen transcripts encoding WRKY transcription factors in both genotypes (Fig. 3A).

Cell walls are one form of defense against fungal pathogens and xylan is a primary component of grass cell walls (Carpita and Gibeaut 1993). To infect plants, pathogens such as $F$. graminearum appear to use xylanases to degrade xylans. During $F$. graminearum infection of barley, fungal gene transcripts encoding xylanases were detected (Güldener et al. 2006). Thus,

\section{A}

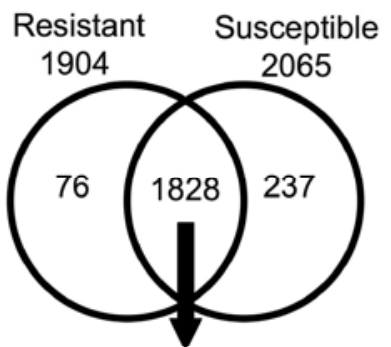

Increased transcript accumulation at either 48 or 96 hai in both genotypes

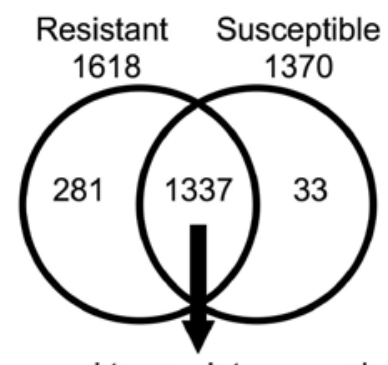

Increased transcript accumulation at 48hai in both genotypes

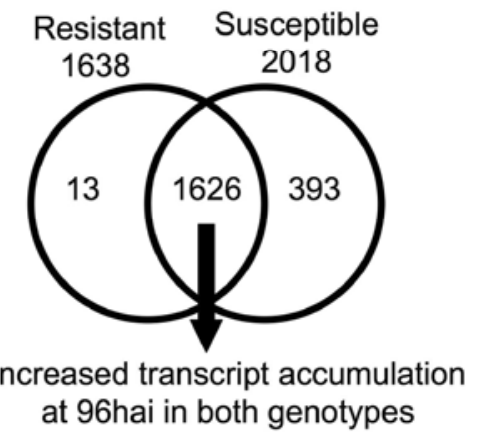

B

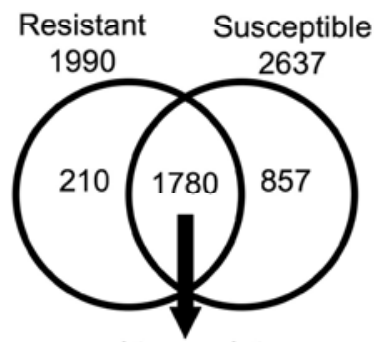

Decreased transcript accumulation at either 48 or 96 hai in both genotypes

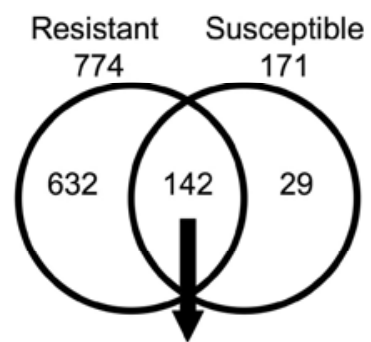

Decreased transcript accumulation at 48 hai in both genotypes

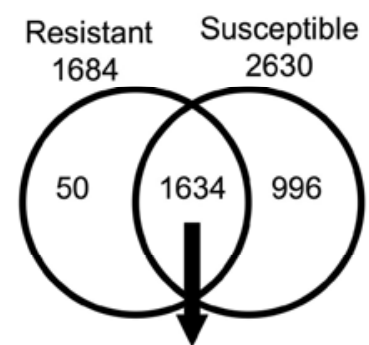

Decreased transcript accumulation at 96 hai in both genotypes

Fig. 2. A, Venn diagrams showing the number of gene transcripts in the resistant and susceptible genotypes that displayed increased or $\mathbf{B}$, decreased transcript accumulation $(P \leq 0.0001, \geq 2.0$ fold) after Fusarium graminearum inoculation compared with mock water-inoculation. 
we searched our data for xylanase inhibitors and found increased accumulation of 10 gene transcripts encoding xylanase inhibitors in the resistant and susceptible wheat genotypes during infection (Fig. 3A). Interestingly, we also found 13 transcripts that were repressed that encode proline-rich proteins that comprise a major component of the plant cell wall (Fig.

Table 2. Induced or repressed gene transcripts detected in a wheat nearisogenic line pair carrying either the $F h b 1$-resistant or -susceptible allele ${ }^{\mathrm{a}}$

\begin{tabular}{lrr}
\hline Class & Induced & Repressed \\
\hline Cell death-related & 9 & 3 \\
Cell wall-related & 39 & 50 \\
Chromatin-related & 1 & 70 \\
Defense response & 314 & 128 \\
Hormone-related & 41 & 27 \\
Membrane-related & 11 & 12 \\
Metabolism & 255 & 224 \\
Miscellaneous & 138 & 235 \\
Photosystem-related & 3 & 27 \\
Regulatory & 161 & 127 \\
Ribosomal protein & 4 & 41 \\
Stress response & 18 & 23 \\
Transporter & 33 & 22 \\
Putative trichothecene detoxification and transport & 28 & 5 \\
Ubiquitination & 4 & 5 \\
Unknown & 769 & 781 \\
Total & 1,828 & 1,780 \\
\hline
\end{tabular}

${ }^{a}$ At 48 and 96 h after Fusarium graminearum inoculation compared with water inoculation.
3B). These results indicate that the cell wall is a primary point of interaction between wheat and $F$. graminearum.

Previous studies have suggested that PCD occurs during $F$. graminearum infection of barley and wheat (Boddu et al. 2007; Desmond et al. 2008). Thus, we examined our data for gene transcripts that encode proteins related to PCD. Nine PCD-related gene transcripts were found to be up-regulated in both genotypes after $F$. graminearum inoculation (Fig. $3 \mathrm{~A})$. Three, one and one transcripts encode homologs to the rice SPOTTED LEAF11, and SPOTTED LEAF7 genes, and tomato pirin gene, respectively. The other four transcripts encode senescence-associated proteins. These genes have been implicated in PCD responses in various plant-pathogen interactions (Kojo et al. 2006; Orzaez et al. 2001; Yamanouchi et al. 2002; Zeng et al. 2004). PCD is also characterized by chromatin degradation and $\mathrm{H}_{2} \mathrm{O}_{2}$ production, and both were found in the wheat stems inoculated with DON (Desmond et al. 2008). We also found 70 chromatin-related genes encoding histones (histone $\mathrm{H} 1, \mathrm{H} 2 \mathrm{~A}$, and $\mathrm{H} 2 \mathrm{~B}$, centromeric histone 3, and histone deacetylase 2) that exhibited decreased accumulation after $F$. graminearum inoculation, indicating a reduction in chromatin function (Fig. 3B). These results indicate that $\mathrm{PCD}$ is functioning during the wheat $-F$. graminearum interaction.

By 96 hai, we observed necrosis and bleaching symptoms on the spikelets of both resistant and susceptible genotypes, indicating a reduction in overall plant biochemical and cellular activity and structure. Corresponding with these phenotypes is

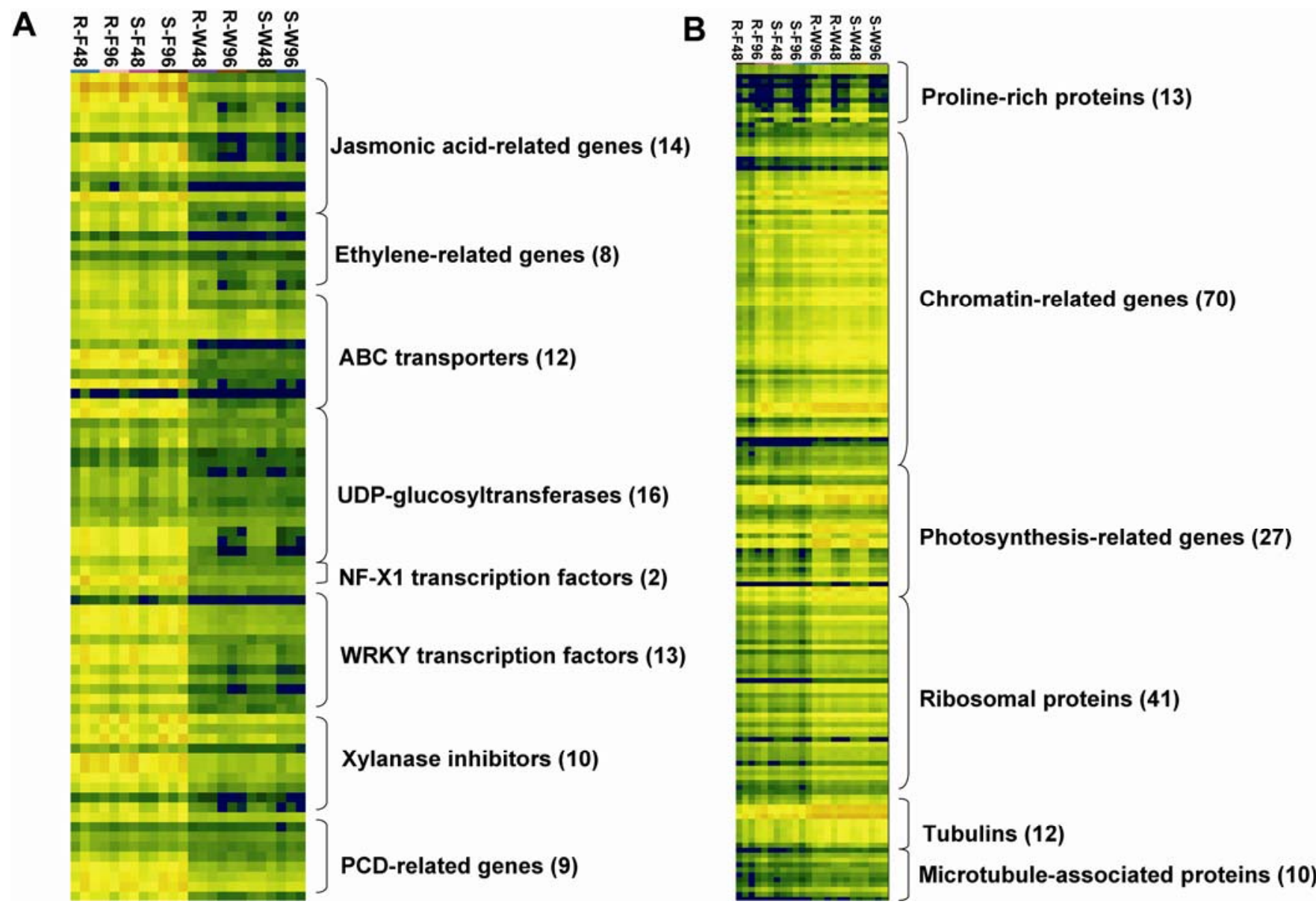

Fig 3. A, Heat maps showing increased or $\mathbf{B}$, decreased abundance $(P \leq 0.0001, \geq 2.0$-fold) of gene transcripts in specific classes in the resistant and susceptible genotypes after Fusarium graminearum inoculation compared with mock water inoculation. The color contrast used in A was slightly different from that used in $\mathrm{B}$ to show those gene transcripts exhibiting low accumulation. $\mathrm{R}$ and $\mathrm{S}=$ resistant and susceptible genotype, respectively; $\mathrm{F}$ and $\mathrm{W}=F$. graminearum and water inoculation, respectively; 48 and $96=\mathrm{h}$ after inoculation. Lighter color indicates greater transcript accumulation. 
the reduced accumulation of 27 gene transcripts encoding photosystem-related functions (e.g., chlorophyll a-b binding protein, photosystem I reaction center subunits, photosystem II reaction center protein, and photosystem II 10-kDa polypeptides) (Fig. 3B). We also identified 41 ribosomal gene transcripts that exhibited reduced accumulation in both resistant and susceptible genotypes, only four ribosomal gene transcripts were increased (Fig. 3B). Moreover, we identified 12 and 10 transcripts encoding tubulins and microtubule-associated proteins, respectively, that were repressed in both genotypes (Fig. 3B). The reduction in these transcripts demonstrates the impact $F$. graminearum infection has on basic cellular functions.

\section{Differential response of wheat NIL carrying either the $F h b 1$ resistant or susceptible allele to $F$. graminearum infection.}

We compared the transcript profiles of the resistant and susceptible genotypes during $F$. graminearum infection and mock water inoculation ( $P \leq 0.0001$; twofold difference). A total of 27 transcripts were differentially expressed between the resistant and susceptible genotypes during either $F$. graminearum, water inoculation, or both (Table 3). Based on the map locations of previously mapped expressed sequence tags (EST) displayed on the Graingenes website, the genetic location of 12 of these genes was identified (Table 3). If a transcript contains a single feature polymorphism (SFP), it affects its affinity to the target probe on the GeneChip and may obscure the transcript accumulation value. Of the 27 transcripts, we detected 13 with at least one SFP. It is possible that those transcripts exhibiting one or more SFP may not be true transcript accumulation differences between the resistant and susceptible genotypes. Subtracting the transcripts with SFP, 10 transcripts exhibited an increase in the resistant genotype compared with the susceptible genotype and four transcripts exhibited a decrease in the resistant genotype compared with the susceptible genotypes (Table 3). The 10 transcripts showing increased accumulation in the resistant genotype encode a proline-rich protein, expansin, NB-ARC, putative band 7 protein, Bowman-Birk trypsin inhibitor, and five unknown proteins. The four transcripts showing decreased accumulation in the resistant genotype encode a histidine-rich $\mathrm{Ca}^{2+}$-binding protein and three unknown proteins. In total, 10 out of 14 of the transcripts that exhibited a difference between the resistant and susceptible genotypes

Table 3. Transcripts that exhibited differential accumulation $(P \leq 0.0001, \geq 2.0$ fold) between plants carrying either the resistant or susceptible $F$ hbl allele after $F$ usarium graminearum and mock water inoculation

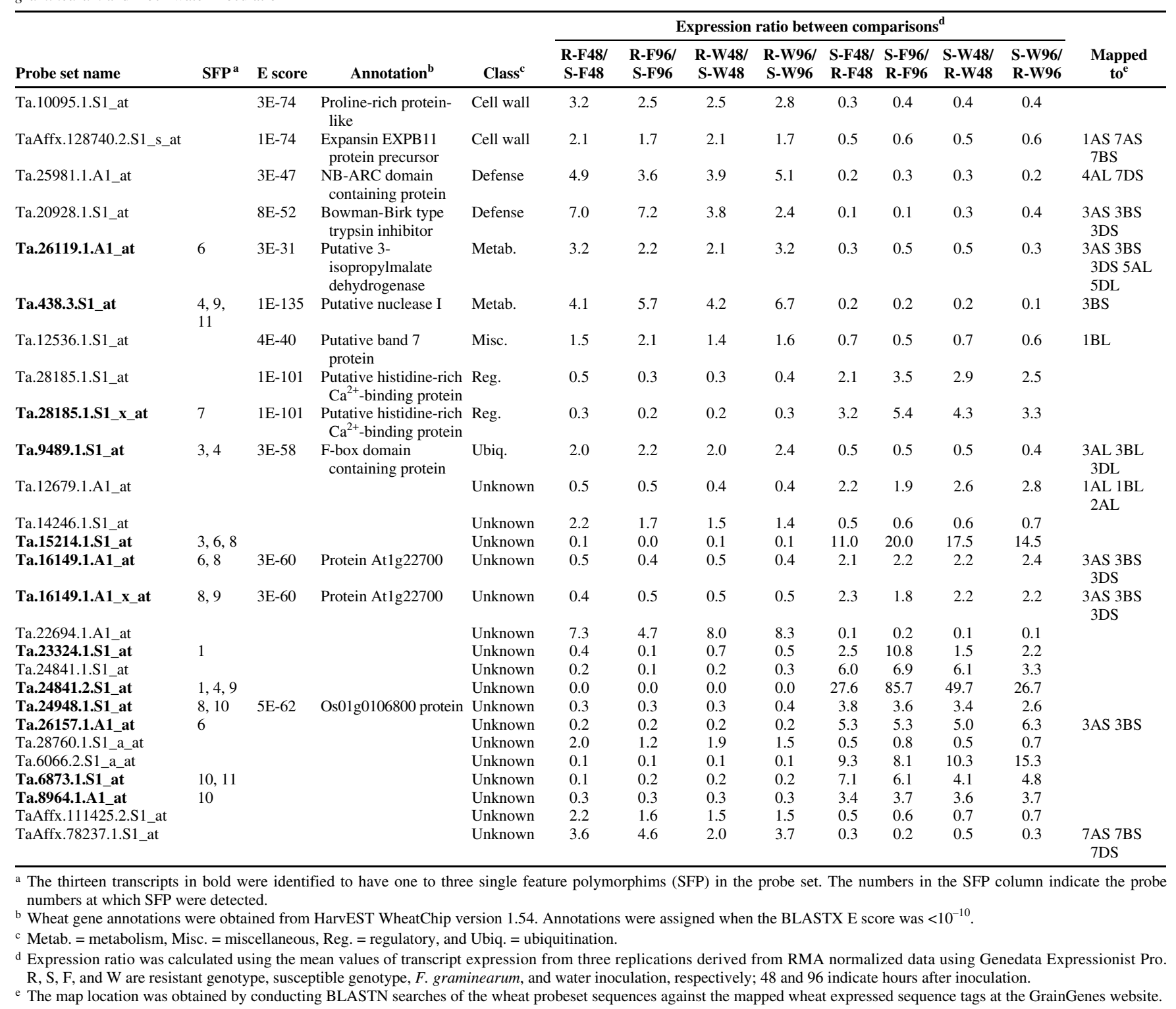


during $F$. graminearum infection also exhibited a difference in the mock water control, indicating that the expression of these genes was independent of $F$. graminearum infection. The remaining four transcripts (Ta.12536.1.S1_at, a putative Band 7 protein; Ta.14246.1.S1_at, unknown; Ta.28760.1.S1_a_at, unknown; and TaAffx.111425.2.S1_at, unknown) were only detected in $F$. graminearum-inoculated plants, indicating that they are dependent upon $F$. graminearum infection. The transcript accumulation differences for these four genes was validated by performing real-time reverse transcription-polymerase chain reaction (RT-PCR) on RNA isolated from the resistant and susceptible genotypes infected with $F$. graminearum (Fig. 4).

\section{DISCUSSION}

We examined transcript accumulation and disease phenotypes in a wheat NIL pair carrying either the resistant or susceptible allele at the Fhbl locus during $F$. graminearum and water inoculation. The Fhbl locus exhibits the greatest effect identified in wheat for type II FHB resistance (Waldron et al. 1999). Lemmens and associates (2005) proposed that Fhbl encodes a DON-glucosyltransferase that functions to detoxify DON by converting it to DON-3-glucoside or, alternatively, Fhbl acts as a regulatory gene that controls the expression of a DON-glucosyltransferase. However, the exact function of $F h b 1$ is not known and it has not yet been cloned. Using the NIL pair for Fhbl allowed us to minimize the genetic background effect and examine disease phenotypes and transcript accumulation patterns mainly caused by resistant and susceptible alleles at the Fhbl locus during $F$. graminearum infection. This study represents a comprehensive examination of the wheat transcriptome during $F$. graminearum infection, a comparison of the response to $F$. graminearum infection in plants carrying the resistant and susceptible alleles at the $F h b 1$ locus, and an opportunity to develop an integrated model for wheat and barley during $F$. graminearum infection.
Fhb1 restricts spread of disease symptoms but does not provide resistance to initial infection.

In our study, the percent FHB disease severity was significantly different between the plants carrying the resistant or the susceptible allele at the Fhbl locus. In the resistant NIL, disease symptoms were restricted to the initially inoculated spikelets and did not spread to the adjacent spikelets over time, confirming type II resistance conferred by the resistant Fhbl allele. Spread of disease symptoms was observed in the susceptible genotype. These results are consistent with published data on Fhbl (Liu et al. 2006). However, we did not observe a significant difference in DON concentration in inoculated spikelets in the resistant genotype compared with the susceptible genotype. In contrast, Lemmens and associates (2005) reported that the wheat Fhbl resistant allele reduced the concentration of DON by conjugating it to glucose and forming DON-3-glucoside, a derivative of DON that exhibits a reduction in toxicity. These authors inoculated spikes of plants carrying either the resistant or susceptible allele for $F h b 1$ with purified DON and sampled them at 7 to 16 days, providing an opportunity for the plants carrying the Fhbl resistance allele to detoxify DON. In our study, we point-inoculated spikes of plants carrying the resistant or susceptible $F h b l$ allele with $F$. graminearum and sampled the inoculated spikelets at 48 and 96 hai, possibly not providing the time necessary for the plants carrying the Fhbl resistant allele to convert DON to DON-3glucoside. We also observed DON accumulation and fungal biomass in the noninoculated spikelets in the susceptible genotype but not in the resistant genotype. Pritsch and associates (2001) showed that the fungus did not grow to adjacent noninoculated spikelets in Sumai3 and Wheaton (a highly susceptible genotype) within 48 hai. Our results indicate that between 48 and 96 hai the fungus infects adjacent noninoculated spikelets in the susceptible genotype. Taken together, our results showed that point-inoculated plants carrying the Fhbl resistant allele exhibited reduced disease severity in the whole spike at maturity but did not result in reduced DON concen-

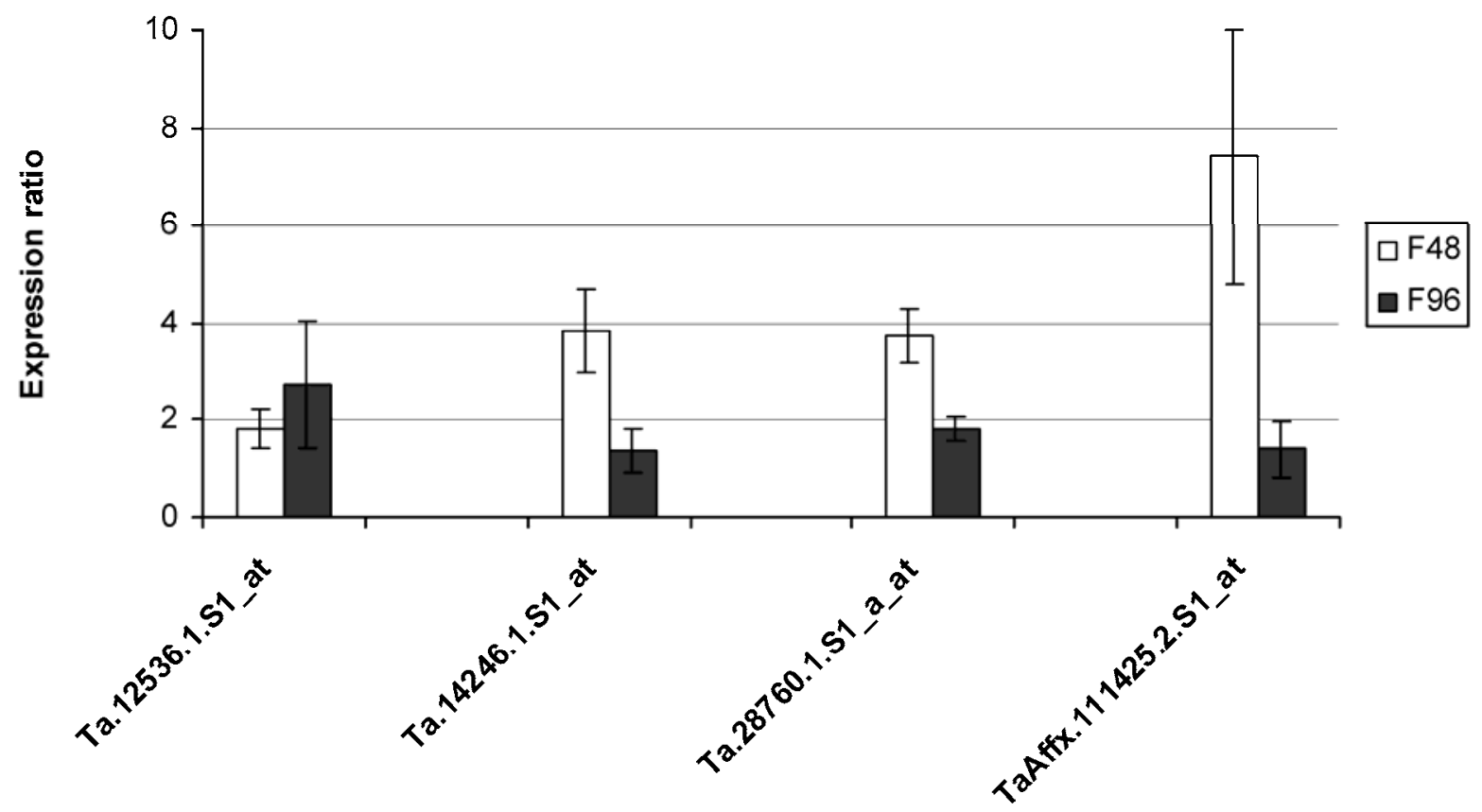

Probe set name

Fig. 4. Real-time reverse transcription-polymerase chain reaction validation of expression ratio between resistant and susceptible genotypes after Fusarium graminearum inoculation. F48 and F96 = $48 \mathrm{~h}$ and $96 \mathrm{~h}$ after $F$. graminearum inoculation, respectively. Each column was the average expression ratio calculated from three biological replications. Error bar shows standard error. 
tration or fungal biomass in the inoculated spikelets during the early stages of infection.

\section{Dynamics of gene expression during the wheat- $F$. graminearum interaction.}

Overall, our results show that the number of gene transcripts exhibiting higher accumulation was moderately increased between 48 and 96 hai, while there was a large increase in the number of transcripts that showed decreased accumulation between 48 and 96 hai. Thus, our results reveal a general trend that wheat tissues induce a high number of gene transcripts during the early stages of infection and an equivalent number of gene transcripts that are repressed later in disease development. Interestingly, members of many gene classes were induced and repressed (Table 2). Previous studies of the host response in wheat and barley to $F$. graminearum infection did not identify many repressed genes. In two studies, three and 16 transcripts exhibited less accumulation in barley after $F$. graminearum inoculation (Boddu et al. 2006 and 2007, respectively), and 16 transcripts exhibited reduced accumulation in wheat after $F$. graminearum infection (Golkari et al. 2007). A potential explanation for the distinct results in the previous studies and the one reported here is the difference in inoculation and sampling methods. In the barley studies (Boddu et al. 2006; 2007), spikes were spray- or dip-inoculated and whole spikes were used for the transcriptome analysis, providing a mixture of infected and uninfected tissues. In the current study, only the central four wheat spikelets were inoculated and sampled for gene-expression analysis, resulting in samples with little healthy tissue. The decrease in the amount of healthy tis- sue used for the RNA preparations in the current study likely resulted in the increased number of transcripts exhibiting decreased accumulation. In the study by Golkari and associates (2007), only the 24-hai timepoint was sampled. In our study, the majority of the genes that exhibited reduced transcript accumulation were found at the 96-hai timepoint, indicating that the timing of reduced transcript accumulation occurs later in disease development.

\section{The wheat- and barley-F. graminearum interaction.}

Wheat and barley are members of the Triticeae family, are highly related, and are hosts of $F$. graminearum. The initial $F$. graminearum growth and infection pathways that eventually result in tissue necrosis are similar in barley and wheat (Fig. 5) (Boddu et al. 2006; 2007; Pritsch et al. 2000). However, they exhibit different resistance phenotypes. Barley exhibits limited tissue bleaching and a natural type II resistance (resistance to spread of the disease in the spike), even in susceptible genotypes (Boddu et al. 2007). In contrast, infected wheat tissues become bleached even in type II resistant genotypes, and susceptible genotypes exhibit spread of the disease symptoms. Thus, a comparison of host response in wheat and barley to $F$. graminearum infection may provide a greater understanding of the interaction between wheat and barley and $F$. graminearum.

In our previous studies examining gene expression in barley during $F$. graminearum infection, a model for the barley- $F$. graminearum interaction was proposed (Boddu et al. 2006, 2007). The basic model states that the interaction is characterized by early (0 to 48 hai), intermediate (48 to 96 hai), and late (96 to 144 hai) stages. We noted that the host response was

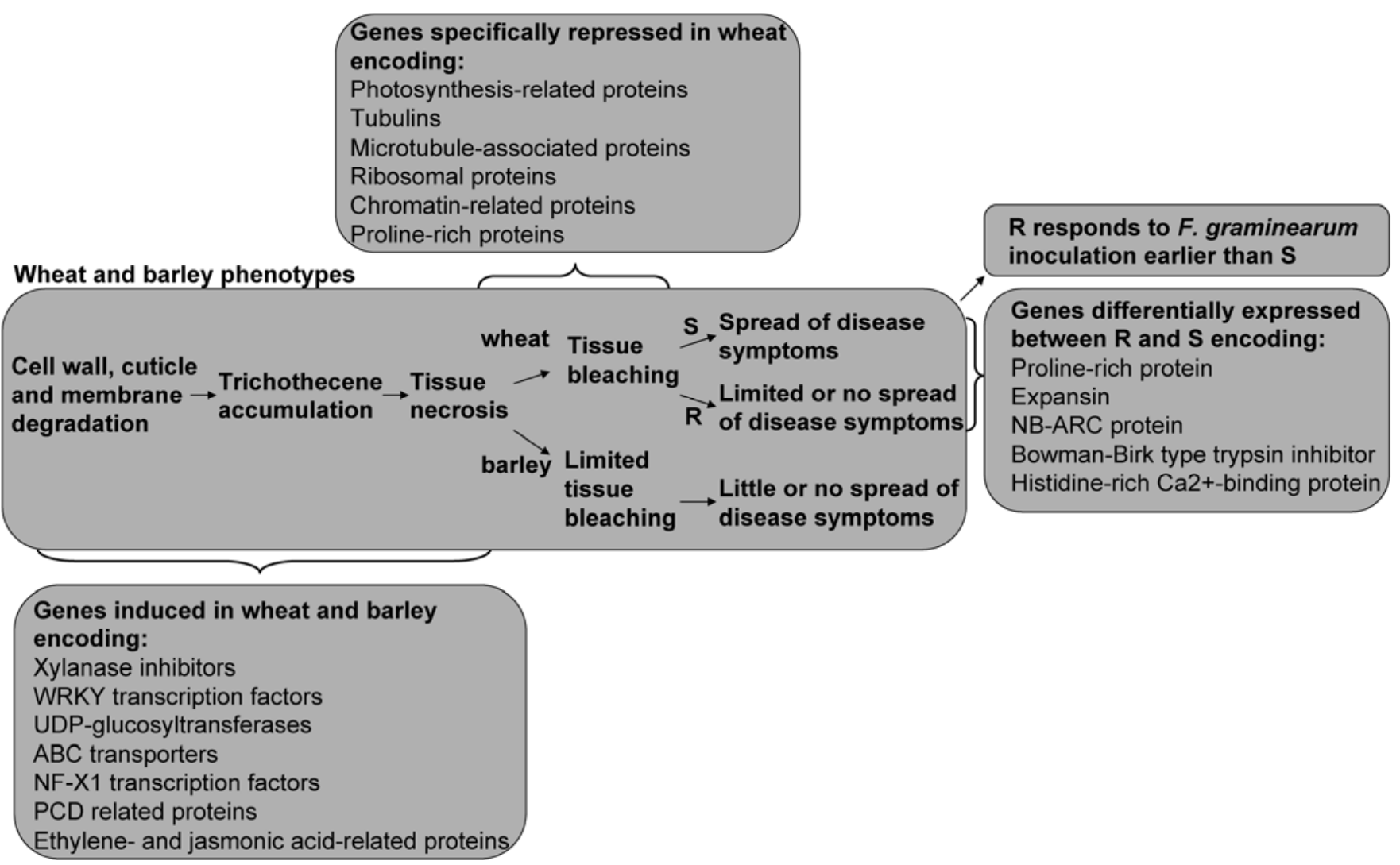

Fig. 5. A model for the wheat- and barley-Fusarium graminearum interaction. Genes induced in wheat and barley were gene transcripts that exhibited increased accumulation in F. graminearum-infected barley (Boddu et al. 2006, 2007) and wheat (this study). Only those gene transcripts that were induced in barley and were predominantly induced in wheat were included. Genes specifically repressed in wheat were gene transcripts that were only found to exhibit reduced transcript accumulation in wheat during $F$. graminearum infection. Genes differentially expressed between resistant and susceptible wheat genotypes were gene transcripts that showed accumulation difference between the genotypes after $F$. graminearum and water inoculation. $\mathrm{R}$ and $\mathrm{S}$ indicate plants carrying the Fhbl resistant or susceptible alleles, respectively. 
greatest (highest number of transcripts detected) in the intermediate stage coincident with the initial analytical detection of DON. In addition, we examined fungal gene expression during $F$. graminearum infection of barley and found accumulation of transcripts encoding cell-, cuticle-, and membrane-degrading enzymes and trichothecene biosynthetic enzymes (Güldener et al. 2006). The majority of these fungal gene products were first observed during the intermediate stage of infection, indicating that the ability to degrade the cuticle, cell walls, and membranes and to synthesize trichothecenes likely aids the fungus in initial infection and colonization of barley spikes. Two general host responses to trichothecene accumulation were proposed (Boddu et al. 2007). One response is to induce genes that encode trichothecene detoxifying and transport functions, providing protection to the toxic effects of trichothecenes. The other general response is to induce genes that are diagnostic for PCD. Thus, PCD likely occurs during $F$. graminearum infection and may result in increased susceptibility due to the necrotrophic phase of $F$. graminearum infection.

We compared the host response in wheat to $F$. graminearum infection (this study) to the host response in barley to $F$. graminearum infection (Boddu et al. 2006, 2007). The differences in inoculation and sampling between wheat and barley will undoubtedly cause differences in the host responses. However, our primary goal was to determine the conserved responses, with a secondary goal of identifying differences. Our approach was to compare the annotations of the gene transcripts detected in wheat and barley during $F$. graminearum infection. The basic model of the barley $-F$. graminearum interaction is supported, with some differences, by the genomewide gene expression profiles observed in the wheat $-F$. graminearum interaction. In the wheat study presented here, we only examined 48 and 96 hai, and precisely placing the events on a timeline of infection was complicated by the lack of multiple timepoints and the integration of the timing of wheat host responses to barley host responses. Nevertheless, we identified a set of host responses that are conserved in barley and wheat during $F$. graminearum infection (Fig. 5).

In addition to the standard defense responses (e.g., expression of genes encoding pathogenesis-related proteins, oxidative burst responses, phenyl propanoid pathway enzymes) observed in most plant-pathogen interactions and in wheat- and barley- $F$. graminearum interactions, wheat and barley exhibit several specialized responses to $F$. graminearum infection (Fig. 5). Similar to barley, wheat responds to initial infection by inducing the expression of xylanase inhibitors to reduce the impact on cell-wall integrity of fungal-derived xylanases and possibly other cell wall-, cuticle-, and membrane-degrading enzymes. In addition, wheat and barley respond to infection by inducing the expression of UDP-glucosyltransferases and ABC transporters that may reduce the impact of trichothecene mycotoxins. In Arabidopsis, UDP-glucosyltransferases have been shown to convert DON to DON-3-glucoside, a less toxic derivative (Poppenberger et al. 2003). In tobacco, overexpression of an $\mathrm{ABC}$ transporter resulted in enhanced resistance to trichothecenes (Jasinski et al. 2003; Sanchez-Fernandez et al. 2001). Handa and associates (2008) proposed that an ABC transporter is a candidate gene for the wheat QTL for FHB resistance located on chromosome 2D. Based on the production of $\mathrm{H}_{2} \mathrm{O}_{2}$ and DNA laddering in wheat inoculated with DON and the induction of PCD-related genes in barley inoculated with $F$. graminearum, PCD has been proposed (Boddu et al. 2007; Desmond et al. 2008). In our current study, we detected wheat gene transcripts (e.g., pirin) that are diagnostic for PCDrelated processes. We also detected a set of regulatory genes encoding NF-X1 and WRKY transcription factors in wheat and barley. In Arabidopsis, Asano and associates (2007) showed that NF-X1 is a negative regulator of trichothecene-induced defense responses. Thus, the NF-X1 genes likely play a role in the defense response to trichothecene accumulation during $F$. graminearum infection. WRKY transcription factors were identified in both wheat and barley and are genes known to play a role in biotic and abiotic stress responses (Liu et al. 2007; Marè et al. 2004; Shimono et al. 2007; Wei et al. 2008) and likely regulate the response to $F$. graminearum infection. Furthermore, both wheat and barley induce genes that are involved with ET and JA biosynthesis or responses or both. JA and ET are usually associated with defense against necrotrophic pathogen invasion and cross-talk between the ET and JA signaling pathways was shown to maximize the host response to the pathogen (Glazebrook 2005; Spoel et al. 2007). Our results indicate that the similar transcript accumulation patterns may relate to the events leading up to necrosis and cell death that are common in both wheat and barley (Fig. 5).

Although many of the induced genes are conserved between wheat and barley, in wheat, we observed the repression of a large set of genes encoding chromatin functions (e.g., histone $\mathrm{H} 1, \mathrm{H} 2 \mathrm{~A}$, and $\mathrm{H} 2 \mathrm{~B}$, centromeric histone 3 , and histone deacetylase 2), ribosomal proteins, tubulin proteins, microtubule-associated proteins, proline-rich proteins, and photosynthetic activities (e.g., chlorophyll a-b binding protein, photosystem I reaction center subunits, photosystem II reaction center subunits, and photosystem II 10-kDa polypeptides) (Fig. 5). Trichothecenes were shown to interact with the peptidyl transferase site of ribosomal proteins, resulting in inhibition of translation (McLaughlin et al. 1977). Although we do not know if repression of ribosomal transcripts is due to the direct action of trichothecenes, our results show that during the wheat $-F$. graminearum interaction genes encoding ribosomal proteins are repressed. Our results also show that genes involved with photosynthesis function are repressed, indicating that chloroplast function is reduced during infection. Indeed, chloroplast degradation has also been linked to PCD during plant-pathogen interactions (Genoud et al. 2002; Williams and Dickman 2008). Thus, our results also indicate that PCD and chloroplast function are related in the wheat $-F$. graminearum interaction. The repression of tubulin, microtubule-associated protein, and proline-rich protein genes, indicates degradation of plant cellular structures. Compared with barley, which exhibits limited tissue bleaching, infected wheat tissues become completely bleached, likely leading to the repression of photosynthesis-related genes and other genes required for cellular structure, protein translation, and chromatin integrity. Thus, these gene transcripts are likely repressed during tissue bleaching in wheat and they are not repressed in barley due to the limited amount of bleaching (Fig. 5). It is possible that the different inoculation and sampling methods between wheat and barley resulted in the different responses. However, it is interesting that the wheat host responses are consistent with the observed disease phenotypes. Taken together, our study revealed many similarities but some important differences in wheat and barley infected with $F$. graminearum and highlighted the utility of examining the response in two hosts to infection by a single pathogen.

\section{Host responses differing between plants carrying either the resistant or susceptible Fhb1 allele.}

The use of a NIL pair carrying either the resistant or susceptible allele for the Fhbl locus in this study provided the opportunity to identify genes that exhibited differential transcript accumulation in the resistant or susceptible genotype and provided the opportunity to identify genetic differences between the genotypes. We identified 14 gene transcripts that exhibited differential accumulation between the plants carry- 
ing the resistant and susceptible alleles for $F h b l$ and 13 additional transcripts that contained one or more SFP. One of the transcripts that exhibited differential accumulation, Ta.20928.1.S1_at, encodes a Bowman-Birk type trypsin inhibitor and was previously mapped as an EST to chromosome 3BS (Table 3). Of the 13 gene transcripts that exhibited multiple SFP, five were previously mapped as EST to chromosome 3BS. These results demonstrate the utility of GeneChip technology to identify genetic and gene expression differences between genotypes.

DON and ergosterol accumulation in the inoculated wheat spikelets on the resistant and susceptible NIL were not quantitatively different $(P<0.01)$ at either 48 or 96 hai. Thus, by analyzing the transcriptome profiles in just the inoculated spikelets, we are likely not able to detect all the genes that were differentially expressed between the genotypes. Nonetheless, our results showed that the resistant genotype exhibited greater numbers of transcripts that exhibited increased and decreased accumulation at 48 hai (Fig. 2). We found more gene transcripts at 96 hai in the susceptible genotype. Overall, these results indicate that the resistant genotype responds early after infection, whereas the susceptible genotype exhibits a slower but eventually greater response to infection. This overall response may play a role in the different phenotypes observed in plants carrying the resistant or susceptible Fhbl allele (Fig. 5).

We also compared our transcript accumulation results with those of other groups that have studied the wheat $-F$. graminearum interaction. Bernardo and associates (2007) examined resistant and susceptible genotypes during $F$. graminearum infection and identified three genes with unknown function that exhibited transcript accumulation differences; however, the genotypes were not isogenic, so a direct comparison was difficult. Ansari and associates (2007) showed that the expression of a bZIP transcription factor exhibited differential accumulation in plants carrying either resistant or susceptible alleles for the Fhbl locus and may play a role in Fhbl-related defense responses. Steiner and associates (2009) identified 14 gene transcripts that exhibited accumulation differences between resistant and susceptible genotypes. Based on the annotations there was no overlap between genes that exhibited differential expression between the resistant and susceptible genotypes in the studies by Bernardo, Steiner, and Ansari and their associates $(2007,2009,2007$, respectively) and our study.

A total of 14 gene transcripts exhibited differential accumulation between the resistant and susceptible genotypes. However, only four were found specifically induced during $F$. graminearum infection and the other 10 are likely involved with the basal defense response. Among these 14 gene transcripts, 10 exhibited increased accumulation in the resistant genotype compared with susceptible ones, and four exhibited decreased accumulation in the resistant genotype. The gene transcripts that exhibited increased accumulation in the resistant genotype encoded cell-wall biogenesis functions (e.g., proline-rich protein, expansin), a Bowman-Birk type trypsin inhibitor, an NBARC protein, a putative band 7 protein, and unknown proteins. Expansins are involved in cell expansion and other processes during cell-wall modification events (Sampedro and Cosgrove 2005), while proline-rich proteins are components of the cell wall (Otte and Farz 2000). Interestingly, proline-rich proteins were generally found to be repressed in both genotypes (Fig. $3 \mathrm{~B})$. The increased accumulation in gene transcripts encoding expansin and proline-rich proteins in the resistant genotype indicates that cell-wall functions may play a role in protecting the resistant genotype. Protease inhibitors have been shown to limit germination and growth of fungal pathogens in wheat and other crops (Cordero et al. 1994) and may be participating in the resistant response. The NB-ARC domain is a signal motif shared by plant resistance genes and regulators of cell death in animals (van der Biezen and Jones 1998), indicating that this gene may play a role in resistance and cell-death responses. The other four gene transcripts encoding a putative histidine-rich $\mathrm{Ca}^{2+}$-binding protein and three unknown proteins exhibited decreased accumulation in the resistant genotype compared with the susceptible genotype. The overall small number of gene transcripts exhibiting differential accumulation between the resistant and susceptible genotypes is likely due to the lack of distinct differences in the disease phenotypes up to 96 hai. Taken together, these genes are characteristic of the differences between the resistant and susceptible responses in wheat (Fig. 5).

\section{MATERIALS AND METHODS}

Plant materials, fungal strain, and growth conditions.

A wheat NIL pair 260-1-1-2 (Fhbl+) and 260-1-1-4 (Fhbl-) carrying resistant and susceptible alleles, respectively, for $F h b l$ was used in this study. Fhbl was originally identified in a wheat recombinant inbred line (RIL) population derived from cv. Sumai $3 \times$ cv. Stoa (Waldron et al. 1999). Sumai 3 carries a type II FHB-resistance QTL (Fhbl or QFhs.ndsu$3 B S$ ) on chromosome 3BS (Liu et al. 2006; Waldron et al. 1999). Stoa is a cultivar that is moderately susceptible to FHB. An FHB-resistant RIL derived from the Sumai 3-Stoa population RI 63, which carries the resistant Fhbl allele, was crossed with an FHB-susceptible line, MN97448. A NIL pair homozygous for the Fhbl region, designated 260-1-1-2 (Fhbl+, resistance allele) and 260-1-1-4 (Fhb1-, susceptible allele), was derived from a self from an $\mathrm{F}_{7}$ line that was heterozygous for the Fhbl region (Pumphrey et al. 2007). J. Anderson (University of Minnesota, St. Paul, MN, U.S.A.) provided this NIL pair to our laboratory.

To genetically characterize the NIL pair, 15 simple sequence repeat markers on chromosome $3 \mathrm{BS}$ positioned from 0 to 71 cM (Somers et al., 2004) were used to genotype the two NIL. Only four of the markers, gwm533, gwm493, barc87, and barc133, positioned between approximately 6 to $16 \mathrm{cM}$, were found polymorphic between the NIL.

The monosporic isolate of the strain $F$. graminearum Butte 86 (provided by R. Dill-Macky, University of Minnesota) was used for fungal inoculations. Butte 86 was deposited at the Fungal Genetics Stock Center (accession number: NRRL38661). It is a DON and 15ADON producer.

The seeds were planted in Scotts MetroMix 200 in 6-inch pots (five seeds per pot) and were grown in a growth chamber at $20^{\circ} \mathrm{C}$ for $16 \mathrm{~h}\left(7 \mathrm{a} . \mathrm{m}\right.$. to 11 p.m.) with light and at $18^{\circ} \mathrm{C}$ for $8 \mathrm{~h}$ (11 p.m. to 7 a.m.) under darkness. The light intensity at pot level was approximately $170 \pm 20 \mu \mathrm{E} \mathrm{m} \mathrm{m}^{-2} \mathrm{~s}^{-1}$. Osmocote 14/14/14 (5 ml) (Marysville, OH, U.S.A.) was applied to each pot at one week after planting. Plants were watered everyday until sampling.

\section{Experimental design.}

Three biological replications of the experiment were conducted with a completely random design. Wheat spikes at anthesis of the NIL pair carrying the resistant or susceptible allele for $F h b l$ were point-inoculated with a freshly prepared spore suspension $\left(10^{5}\right.$ macroconidia per milliliter in $0.2 \%$ [vol/vol] Tween 20) or with water in Tween 20 (mock control) at anthesis. A pipette was used to inoculate $10 \mu \mathrm{l}$ of inoculum (1,000 spores) to two spikelets on the central two rows of a spike. The wheat spikes were covered with a clear plastic bag until sampling. The inoculated spikelets and the adjacent noninoculated spikelets were sampled at 48 and 96 hai. Inoculations and sampling were conducted at 9 a.m. ( $2 \mathrm{~h}$ into the light 
cycle). Inoculated spikelets from 10 spikes for each genotypetreatment-timepoint-replication were sampled for RNA isolation. A total of 24 samples (two genotypes, two treatments, two timepoints, and three replications) were obtained for the RNA isolations.

\section{Disease severity on wheat spikes \\ after $\boldsymbol{F}$. graminearum inoculation.}

Wheat carrying the $F h b 1$ resistant or susceptible allele were grown and point-inoculated as described above, were covered with clear plastic bags for 2 days, and were scored at 21 dai. Three replications with 40 plants per genotype per replication were examined. Percent disease severity was obtained by counting the number of diseased spikelets versus the total number of spikelets. $t$-Tests were performed between the resistant and susceptible NIL to determine statistical significance.

\section{Determination of DON and ergosterol concentration.}

For each combination of genotype, treatment, timepoint, and replication, the same two rows of inoculated wheat spikelets (not including the rachis) used for the RNA isolations were used for DON and ergosterol analysis. DON and ergosterol concentration was also determined on two noninoculated spikelets that were adjacent (one above and one below, combined for assays) to the inoculated spikelets. DON concentration was measured by gas chromatography and expressed as parts per million (ppm) (Mirocha et al. 1994, 1998). Ergosterol concentration was determined following standard protocols (Dong et al. 2006).

\section{Affymetrix GeneChip wheat genome array.}

The wheat GeneChip (Affymetrix, Santa Clara, CA, U.S.A.) consists of 61,127 probe sets representing 55,052 gene transcripts. It was designed from sequence information from the Triticum aestivum UniGene Build \#38 of publicly available EST (build date April 24, 2004), EST from the wheat species T. monococcum, T. turgidum, and Aegilops tauschii, and GenBank full-length mRNAs from all species through May 18, 2004 (Affymetrix website). EST from 210 libraries were used to design the Wheat GeneChip. A total of 104 libraries were from abiotic or biotic stress conditions, seven of which were from $F$. graminearum-inoculated spikes. The number of EST from the stress and $F$. graminearum-treated libraries were 39 and $2.6 \%$ of the total, respectively.

\section{RNA extraction, labeling, and \\ GeneChip wheat genome array hybridizations.}

Total RNA was isolated, labeled, and hybridized to the Affymetrix Wheat GeneChip following the standard protocol described by Boddu and associates (2006). The Biomedical Image Processing Facility at the University of Minnesota performed the GeneChip hybridizations, washing and scanning according to Affymetrix procedures.

\section{GeneChip data analysis.}

GeneChip data analysis was conducted using GeneData Expressionist Pro version 4.5 (GeneData, San Francisco). The data was first normalized by robust multichip analysis (Irizarry et al. 2003), using the Refiner module in Expressionist. Correlation coefficients were calculated between replications, and they ranged from 97 to $99 \%$. An N-way analysis of variance test $(P$ value $\leq 0.0001)$ was conducted using the Analyst module to identify transcripts exhibiting differences in accumulation by genotype effect (resistant or susceptible), treatment effect ( $F$. graminearum or water mock), time effect (48 or 96 hai), genotype by treatment, genotype by time, treatment by time, and genotype by treatment by time effect. A false discov- ery rate of $0.04 \%$ was calculated based on the method of Benjamini and Hochberg (1995). Transcripts showing more than twofold differential accumulation between treatments and genotypes were selected.

A list of 32,578 unreliable probe sets have been identified on the wheat chip (U. Baumann, personal communication). These unreliable probe sets contain $5^{\prime}$ probe sets, which often hybridize very poorly as opposed to the usual $3^{\prime}$ anchored probe sets. We removed the above unreliable probe sets from our analysis.

Gene annotations were based on the probe set annotations at HarvEST, using HarvEST WheatChip Version 1.45. The functional classes included cell death-related, cell wall-related, chromatin-related, defense response, putative trichothecene detoxification and transport, hormone-related, membrane-related, metabolism, miscellaneous, photosystem-related, regulatory, ribosomal protein, stress response, transporter, ubiquitination, and unknown. Wheat genes were placed into a functional class if the $\mathrm{E}$ value was $\leq 10^{-10}$; otherwise they were regarded as unknown. All the probe sets on the wheat array were blasted against the $F$. graminearum genome sequence at the Broad Institute's $F$. graminearum database. Genes were classified as $F$. graminearum if the percent nucleotide identity to the $F$. graminearum genome sequence was $\geq 95 \%$ and the $\mathrm{E}$ value was $\leq 10^{-84}$. In all, $65 F$. graminearum probe sets were removed from further analysis.

All data including CEL, DAT, CHP, and EXP files have been uploaded to the Plant Expression database (PLEXdb). The accession number for the experiment is TA20.

\section{Real-time RT-PCR validation.}

Real-time RT-PCR was used to validate the microarray results for the four gene transcripts that showed differential expression ( $\geq 2.0$-fold) between the resistant and susceptible genotypes specifically after $F$. graminearum inoculation. Primers were designed with Primer Express Software, according to standard parameters for real-time RT-PCR assays (Bio-Rad Laboratories, Hercules, CA, U.S.A.). Primer sequences were:
Ta.12536.1.S1_at
F: GCCGCATACCAAGCAAGAGTAG,
R: AGTCATAGCTCAAGGCAGCCTG
Ta.14246.1.S1_at
F: TATTCGGACCCCTTTTGCAC,
R: TCGGTTAATCCTCTCCCATAGG
Ta.28760.1.S1_a_at
F: TCTTCGACTGGCACTTCAACTG,
R: GATAGGACCCCAGACAGCAAAA
TaAffx.111425.2.S1_at
F: AGGAGGCGCTGTCTGAATCTAT;
R: GCCCCAGCATACAGTTGAAAC
wheat actin
F: CCGGCATTGTCCACATGAA;
R: CCAAAAGGAAAAGCTGAACCG.

Bio-Rad iScript cDNA synthesis kit (170 to 8,891) was used to synthesize cDNA from the same RNA samples used for microarray experiments. Real-time RT-PCR was carried out with the Bio-Rad Chromo 4 real-time system, using 96-well plates. Bio-Rad iTaq SYBR Green supermix with Rhodamine X was used (cycling conditions: $95^{\circ} \mathrm{C}, 3 \mathrm{~min} ; 40$ cycles of $95^{\circ} \mathrm{C}, 15 \mathrm{~s}$ and $60^{\circ} \mathrm{C}, 45 \mathrm{~s} ; 95^{\circ} \mathrm{C}, 1 \mathrm{~min} ; 58^{\circ} \mathrm{C}, 1 \mathrm{~min}$; melting curve from 58 to $98^{\circ} \mathrm{C}$, read every $0.5^{\circ} \mathrm{C}$, hold $10 \mathrm{~s}$; end). RNA from the resistant and susceptible genotypes inoculated with $F$. graminearum from all three biological replications used in the GeneChip experiment were used for the validation. Transcript accumulation of the four target genes and the positive control gene wheat actin were measured for $F$. graminearum-treated RNA samples of a single biological replication on each 96well plate. Each genotype-treatment-timepoint combination was 
technically replicated three times. Negative control wells containing the reaction mixture with water as template were included on each plate. MJ Opticon Monitor Software version 3.1 was used for visualizing and analyzing the real-time RTPCR data (Bio-Rad Laboratories). The obtained threshold cycle $(\mathrm{Ct})$ values were used to calculate the fold change in transcript accumulation $=2^{\wedge}\left(\Delta \mathrm{Ct}_{\text {target }}-\Delta \mathrm{Ct}_{\text {actin }}\right)$.

\section{SFP analysis.}

SFP were detected between the resistant and susceptible genotypes by applying an algorithm described by Cui and associates (2005) and Rostoks and associates (2005), with modifications.

\section{ACKNOWLEDGMENTS}

We thank J. Anderson for providing the wheat NIL pair and R. DillMacky for providing the Fusarium graminearum inoculum. We also acknowledge Y. Dong for conducting the DON and ergosterol assays. We thank W. Xu and Z. Tu at the Supercomputing Institute for bioinformatics assistance. This work was supported by grants to G. J. Muehlbauer from the U.S. Wheat and Barley Scab Initiative (United States Department of Agriculture-Agricultural Research Service) and Minnesota Small Grains Initiative, and a College of Food, Agriculture and Natural Resources Sciences Graduate Student Fellowship and University of Minnesota Graduate School Doctoral Dissertation Fellowship to H. Jia.

\section{LITERATURE CITED}

Anderson, J. A., Stack, R. W., Liu, S., Waldron, B. L., Fjeld, A. D., Coyne, C., Moreno-Sevilla, B., Fetch, J. M., Song, Q. J., Cregan, P. B., and Frohberg, R. C. 2001. DNA markers for Fusarium head blight resistance QTLs in two wheat populations. Theor. Appl. Genet. 102:1164-1168.

Ansari, K. I., Walter, S., Brennan, J. M., Lemmens, M., Kessans, S. McGahern, A., Egan, D., and Doohan, F. M. 2007. Retrotransposon and gene activation in wheat in response to mycotoxigenic and non-mycotoxigenic-associated Fusarium stress. Theor. Appl. Genet. 114:927-937.

Asano, T., Masuda, D., Yasuda, M., Nakashita, H., Kudo, T., Kimura, M., Yamaguchi, K., and Nishiuchi, T. 2007. AtNFXL1, an Arabidopsis homologue of the human transcription factor NF-X1, functions as a negative regulator of the trichothecene phytotoxin-induced defense response. Plant J. 53:450-464.

Bai, G., and Shaner, G. 2004. Management and resistance in wheat and barley to Fusarium head blight. Annu. Rev. Phytopathol. 42:135-161.

Bai, G., Kolb, F. L., Shaner, G., and Domier, L. L. 1999. Amplified fragment length polymorphism markers linked to a major quantitative trait locus controlling scab resistance in wheat. Phytopathology 89:343-348.

Benjamini, Y., and Hochberg, Y. 1995. Controlling the false discovery rate: A practical and powerful approach to multiple testing. J. R. Stat. Soc. B. 57:289-300

Bernardo, A., Bai, G., Guo, P., Xiao, K., Guenzi, A. C., and Ayoubi, P. 2007. Fusarium graminearum-induced changes in gene expression between Fusarium head blight-resistant and susceptible wheat cultivars. Funct. Integr. Genomics 7:69-77.

Boddu, J., Cho, S., Kruger, W. M., and Muehlbauer, G. J. 2006. Transcriptome analysis of the barley-Fusarium graminearum interaction. Mol. Plant-Microbe Interact. 19:407-417.

Boddu, J., Cho, S., and Muehlbauer, G. J. 2007. Transcriptome analysis of trichothecene-induced gene expression in barley. Mol. Plant-Microbe Interact. 20:1364-1375.

Buerstmayr, H., Lemmens, M., Hartl, L., Doldi, L., Steiner, B., Stierschneider, M., and Ruckenbauer, P. 2002. Molecular mapping of QTLs for Fusarium head blight resistance in spring wheat. I. Resistance to fungal spread (Type II resistance). Theor. Appl. Genet. 104:84-91.

Bushnell, W. R., Hazen, B. E., and Pritsch, C. 2003. Histology and physiology of Fusarium Head Blight. Pages 44-83 in: Fusarium Head Blight of Wheat and Barley. K. J. Leonard and W. R. Bushnell, eds. American Phytopathology Society Press, St. Paul, MN, U.S.A.

Carpita, N. C., and Gibeaut, D. M. 1993. Structural models of primary cell walls in flowering plants: Consistency of molecular structure with the physical properties of the walls during growth. Plant J. 3:1-30.

Close, T. J., Wanamaker, S. I., Caldo, R. A., Turner, S. M., Ashlock, D. A., Dickerson, J. A., Wing, R. A., Muehlbauer, G. J., Kleinhofs, A., and Wise, R. P. 2004. A new resource for cereal genomics: $22 \mathrm{~K}$ barley GeneChip comes of age. Plant Physiol. 134:960-968.

Cordero, M. J., Raventos, D., and San Segundo, B. 1994. Expression of a maize proteinase inhibitor gene is induced in response to wounding and fungal infection: Systemic wound-response of a monocot gene. Plant J. 6:141-150.

Cui, X., Xu, J., Asghar, R., Condamine, P., Svensson, J. T., Wanamaker, S., Stein, N., Roose, M., and Close, T. J. 2005. Detecting single-feature polymorphisms using oligonucleotide arrays and robustified projection pursuit. Bioinformatics 21:3852-3858.

Desjardins, A. E. 2006. Fusarium Mycotoxins: Chemistry, Genetics, and Biology. American Phytophthological Society, St. Paul, MN, U.S.A.

Desjardins, A. E., and Hohn, T. M. 1997. Mycotoxins in plant pathogenesis. Mol. Plant-Microbe Interact. 10:147-152.

Desmond, O. J., Manners, J. M., Stephens, A. E., Maclean, D. J., Schenk, P. M., Gardiner, D. M., Munn, A. L., and Kazan, K. 2008. The Fusarium mycotoxin deoxynivalenol elicits hydrogen peroxide production, programmed cell death and defence responses in wheat. Mol. Plant Path. 9:435-445.

Dong, Y., Steffenson, B. J., and Mirocha, C. J. 2006. Analysis of ergosterol in single kernel and ground grain by gas chromatography-mass spectrometry. J. Agric. Food Chem. 54:4121-4125.

Genoud, T., Buchala, A. J., Chua, N. H., and Metraux, J. P. 2002. Phytochrome signalling modulates the SA-perceptive pathway in Arabidopsis. Plant J. 31:87-95.

Glazebrook, J. 2005. Contrasting mechanisms of defense against biotrophic and necrotrophic pathogens. Annu. Rev. Phytopathol. 43:205-227.

Golkari, S., Gilbert, J., Prashar, S., and Procunier, J. D. 2007. Microarray analysis of Fusarium graminearum-induced wheat genes: Identification of organ-specific and differentially expressed genes. Plant Biotechnol. J. 5:38-49.

Güldener, U., Seong, K. Y., Boddu, J., Cho, S., Trail, F., Xu, J. R., Adam, G., Mewes, H. W., Muehlbauer, G. J., and Kistler, H. C. 2006. Development of a Fusarium graminearum Affymetrix GeneChip for profiling fungal gene expression in vitro and in planta. Fungal Genet. Biol. 43:316-325.

Handa, H., Namiki, N., Xu, D., and Ban, T. 2008. Dissecting of the FHB resistance QTL on the short arm of chromosome 2D using a comparative genomic approach: From QTL to candidate gene. Mol. Breed. 22:71-84.

Hill-Ambroz, K. , Webb, C. A. , Matthews, A. R. , Li, W. , Gill, B. S., and Fellers, J. P. 2006. Expression analysis and physical mapping of a cDNA library of Fusarium head blight infected wheat spikes. Crop Sci. 46:S15-S26.

Irizarry, R. A., Hobbs, B., Collin, F., Beazer-Barclay, Y. D., Antonellis, K. J., Scherf, U., and Speed, T. P. 2003. Exploration, normalization, and summaries of high density oligonucleotide array probe level data. Biostatistics 4:249-264.

Jansen, C., von Wettstein, D., Schafer, W., Kogel, K. H., Felk, A., and Maier, F. J. 2005. Infection patterns in barley and wheat spikes inoculated with wild-type and trichodiene synthase gene disrupted Fusarium graminearum. Proc. Natl. Acad. Sci. U. S. A. 102:16892-16897.

Jasinski, M., Ducos, E., Martinoia, E., and Boutry, M. 2003. The ATP-binding cassette transporters: Structure, function and gene family comparison between rice and Arabidopsis. Plant Physiol. 131:1169-1177.

Johnson, D. D., Flaskerud, G. K., Taylor, R. D., and Styanarayana, V. 2003. Quantifying Economic Impacts of Fusarium Head Blight in Wheat. Pages 461-483 in: Fusarium Head Blight of Wheat and Barley, K. J. Leonard and W. R. Bushnell, eds. American Phytopathological Society Press, St. Paul, MN, U.S.A.

Kang, Z., and Buchenauer, H. 2000. Ultrastructural and cytochemical studies on cellulose, xylan and pectin degradation in wheat spikes infected by Fusarium culmorum. Phytopathol. Z. 148:263-275.

Kojo, K., Yaeno, T., Kusumi, K., Matsumura, H., Fujisawa, S., Terauchi, R., and Iba, K. 2006. Regulatory mechanisms of ROI generation are affected by rice $s p l$ mutations. Plant Cell Physiol. 47:1035-1044.

Kong, L., Anderson, J. M., and Ohm, H. W. 2005. Induction of wheat defense and stress-related genes in response to Fusarium graminearum. Genome 48:29-40.

Lemmens, M., Scholz, U., Berthiller, F., Dall'Asta, C., Koutnik, A., Schumacher, R., Adam, G., Buerstmayr, H., Mesterhazy, A., and Krska, R. 2005. The ability to detoxify the mycotoxin deoxynivalenol colocalizes with a major quantitative trait locus for Fusarium head blight resistance in wheat. Mol. Plant-Microbe Interact. 18:1318-1324.

Liu, S., Zhang, X., Pumphrey, M. O., Stack, R. W., Gill, B. S., and Anderson, J. A. 2006. Complex microcolinearity among wheat, rice, and barley revealed by fine mapping of the genomic region harboring a major QTL for resistance to Fusarium head blight in wheat. Funct. Intgr. Genomic 6:83-89.

Liu, X., Bai, X., Wang, X., and Chu, C. 2007. OsWRKY71, a rice transcription factor is involved in rice defense response. J. Plant Physiol. 164:969-979.

Marè, C., Mazzucotelli, E., Crosatti, C., Francia, E., Stanca, A. M., and Cattivelli, L. 2004. Hv-WRKY38: A new transcription factor involved in cold- and drought-response in barley. Plant Mol. Biol. 55:399-416 
Masuda, D., Ishida, M., Yamaguchi, K., Yamaguchi, I., Kimura, M., and Nishiuchi, T. 2007. Phytotoxic effects of trichothecenes on the growth and morphology of Arabidopsis thaliana. J. Exp. Bot. 58:1617-1626.

McLaughlin, C. C., Vaughn, M. H., Campbell, J. M., Wei, C. M., Stafford, M. E., and Hansin, B. S. 1977. Inhibition of protein synthesis by trichothecenes. Pages 263-273 in: Mycotoxins in human and animal health. H. V. Rodricks, M. A. Hesseltine, and M. A. Mehlman, eds. Pathotoxin Publishers, Park Forest South, IL, U.S.A.

McMullen, M., Jones, R., and Gallenberg, D. 1997. Scab of wheat and barley: A re-emerging disease of devastating impact. Plant Dis. $81: 1340-1348$

Mesterhazy, A. 1995. Types and components of resistance to Fusarium head blight of wheat. Plant Breed. 114:377-386.

Mirocha, C. J., Xie, W., Xu, Y., Wilcoxson, R. D., Woodward, R. P., Etebarian, R. H., and Behele, G. 1994. Production of trichothecene mycotoxins by Fusarium graminearum and Fusarium culmorum on barley and wheat. Mycopathologia 128:19-23.

Mirocha, C. J., Kolaczkowski, E., Xie, W., Yu, H., and Jelen, H. 1998. Analysis of deoxynivalenol and its derivatives (batch and single kernel) using gas chromatography/mass spectrometry. J. Agric. Food Chem. 46:1414-1418

Muhitch, M. J., McCormick, S. P., Alexander N. J., and Hohn, T. M. 2000. Transgenic expression of the Tri101 or PDR5 gene increases resistance of tobacco to the phytotoxic effects of the trichothecene 4,15 diacetoxyscirpenol. Plant Sci. 157:201-207.

Orzaez, D., de Jong, A. J., and Woltering, E. J. 2001. A tomato homologue of the human protein PIRIN is induced during programmed cell death. Plant Mol. Biol. 46:459-468.

Otte, O., and Farz, W. 2000. Characterization and oxidative in vitro crosslinking of an extensin-like protein and a proline-rich protein purified from chickpea cell walls. Phytochemistry 53:1-5.

Parry, D. W., Jenkinson, P., and McLeod, L. 1995. Fusarium ear blight (scab) in small grain cereals-A review. Plant Pathol. 44:207-238.

Poppenberger, B., Berthiller, F., Lucyshyn, D., Sieberer, T., Schuhmacher, R., Krska, R., Kuchler, K., Glossl, J., Luschnig, C., and Adam, G. 2003. Detoxification of the Fusarium mycotoxin deoxynivalenol by a UDPglucosyltransferase from Arabidopsis thaliana. J. Biol. Chem. 278:47905-47914.

Pritsch, C., Muehlbauer, G. J., Bushnell, W. R., Somers, D. A., and Vance, C. P. 2000. Fungal development and induction of defense response genes during early infection of wheat spikes by Fusarium graminearum. Mol. Plant-Microbe Interact. 13:159-169.

Pritsch, C., Vance, C. P., Bushnell, W. R., Somers, D. A., Hohn, T. M., and Muehlbauer, G. J. 2001. Systemic expression of defense response genes in wheat spikes as a response to Fusarium graminearum infection. Physiol. Mol. Plant Pathol. 58:1-12.

Proctor, R. H., Hohn, T. M., and McCormick, S. P. 1995. Reduced virulence of Gibberella zeae caused by disruption of a trichothecene toxin biosynthetic gene. Mol. Plant-Microbe Interact. 8:593-601.

Pumphrey, M. O., Bernardo, R., and Anderson, J. A. 2007. Validating the Fhb1 QTL for Fusarium head blight resistance in near-isogenic wheat lines developed from breeding populations. Crop Sci. 47:200-206.

Rostoks, N., Borevitz, J. O., Hedley, P. E., Russell, J., Mudie, S., Morris, J., Cardle, L., Marshall, D. F., and Waugh, R. 2005. Single-feature polymorphism discovery in the barley transcriptome. Genome Biol. 6:R54.

Sampedro, J., and Cosgrove, D. J. 2005. The expansin superfamily. Genome Biol. 6:242.
Sanchez-Fernandez, R., Davies, T. G. E., Coleman, J. O. D., and Rea, P. A 2001. The Arabidopsis thaliana ABC protein super family, a complete inventory. J. Biol. Chem. 276:30231-30244.

Shimono, M., Sugano, S., Nakayama, A., Jiang, C.-J., Ono, K., Toki, S., and Takatsuji, H. 2007. Rice WRKY45 plays a crucial role in benzothiadiazole-inducible blast resistance. Plant Cell 19:2064-2076.

Somers, D. J., Isaac, P., and Edwards, K. 2004. A high-density microsatellite consensus map for bread wheat (Triticum aestivum L.). Theor. Appl. Genet. 109:1105-1114.

Spoel, S. H., Johnson, J. S., and Dong, X. 2007. Regulation of tradeoffs between plant defenses against pathogens with different lifestyles. Proc. Natl. Acad. Sci. U.S.A. 104:18842-18847.

Steiner, B., Kurz, H., Lemmens, M., and Buerstmayr, H. 2009. Differential gene expression of related wheat lines with contrasting levels of head blight resistance after Fusarium graminearum inoculation. Theor. Appl. Genet. 118:753-764.

van der Biezen, E. A., and Jones, J. D. 1998. The NB-ARC domain: A novel signalling motif shared by plant resistance gene products and regulators of cell death in animals. Curr. Biol. 8:R226-227.

Waldron, B. L., Moreno-Sevilla, B., Anderson, J. A., Stack, R. W., and Frohberg, R. C. 1999. RFLP mapping of QTL for Fusarium head blight resistance in wheat. Crop Sci. 39:805-811

Walter, S., Brennan, J. M., Arunachalam, C., Ansari, K. I., Hu, X., Khan M. R., Trognitz, F., Trognitz, B., Leonard, G., Egan, D., and Doohan, F. M. 2008. Components of the gene network associated with genotypedependent response of wheat to the Fusarium mycotoxin deoxynivalenol. Funct. Integr. Genomic 8:421-427.

Wei, W., Zhang, Y., Han, L., Guan, Z., and Chai, T. 2008. A novel WRKY transcriptional factor from Thlaspi caerulescens negatively regulates the osmotic stress tolerance of transgenic tobacco. Plant Cell Rep. 27:795-803.

Williams, B., and Dickman, M. 2008. Plant programmed cell death: Can't live with it; can't live without it. Mol. Plant Path. 9:531-534.

Yamanouchi, U., Yano, M., Lin, H., Ashikari, M., and Yamada, K. 2002. A rice spotted leaf gene, $\mathrm{Spl7}$, encodes a heat stress transcription factor protein. Proc. Natl. Acad. Sci. U.S.A. 99:7530-7535.

Zeng, L.-R., Qu, S., Bordeos, A., Yang, C., Baraoidan, M., Yan, H., Xie, Q., Nahm, B. H., Leung, H., and Wang, G.-L. 2004. Spotted leaf11, a negative regulator of plant cell death and defense, encodes a Ubox/Armadillo repeat protein endowed with E3 ubiquitin ligase activity. Plant Cell 16:2795-2808.

Zhou, W., Kolb, F. L., Bai, G., Shaner, G., and Domier, L. L. 2002. Genetic analysis of scab resistance QTL in wheat with microsatellite and AFLP markers. Genome 45:719-727.

Zhou, W., Kolb, F. L., and Riechers, D. E. 2005. Identification of proteins induced or upregulated by Fusarium head blight infection in the spikes of hexaploid wheat (Triticum aestivum). Genome 48:770-780.

\section{AUTHOR-RECOMMENDED INTERNET RESOURCES}

Graingenes database: wheat.pw.usda.gov/GG2/index.shtml

Affymetrix website: www.affymetrix.com/index.affx

HarvEST database: harvest.ucr.edu

Broad Institute's Fusarium comparative genomics database: www.broad.mit.edu/annotation/genome/fusarium_graminearum PLEXdb plant expression database: www.plexdb.org 